\title{
Las TIC en la formación inicial docente
}

\author{
Sonia Amparo Salazar Aristizábal \\ Profesora Facultad de Educación \\ Universidad Surcolombiana \\ sonia.salazar@usco.edu.co
}

La sociedad de la información y el conocimiento viene dada por un cambio de paradigma que se centra en el acceso y uso de las tecnologías. Según la UNESCO (2003b y 2005 citado por Ramírez 2012: 48) "la sociedad del conocimiento es aquella que trata de las capacidades para identificar, producir, procesar, transformar, difundir y utilizar la información para construir y aplicar el conocimiento para el desarrollo humano, con una visión social que propicie la autonomía y englobe la pluralidad, integración, solidaridad y participación".

Por su parte las Tecnologías de la Información y la Comunicación (TIC) se refieren a una amplia gama de servicios, aplicaciones y tecnologías que utilizan diversos equipos (hardware) y programas informáticos (software) y que a menudo se transmiten a través de redes de telecomunicaciones (netware) para la recolección, almacenamiento, procesamiento, transmisión y visualización de la infor-mación y comunicación". (Unión Europea, 2001, citado por Ramírez, 2012: 26).

La sociedad de la información y el conocimiento, considerada por los expertos como la tercera revolución del saber, cambia totalmente la pedagogía, tal como lo hizo en el momento en que emergió la imprenta en el renacimiento después de que los griegos inventaron la Pideia. (Serres, 2012). Esta nueva sociedad requiere el desarrollo de un conjunto de habilidades y destrezas en los futuros docentes, encargados de guiar la nueva generación que desde edades tempranas ha estado expuesta al uso de tecnologías digitales.

El papel del maestro ha sido el de alfabetizar, término que ha evolucionado con el correr del tiempo; en su significado más tradicional la alfabetización es entendida como la capacidad de saber leer y escribir textos codificados a través de símbolos gráficos; actualmente con la aparición de formas de representación más complejas, como el lenguaje audiovisual o el multimedia podemos entender la alfabetización como la adquisición y dominio de las competencias que permiten el uso de los símbolos de representación de la cultura en sus múltiples formas de lenguaje. (Area, 2012).

Por tanto un sujeto alfabetizado en las nuevas formas culturales, además de leer y escribir textos impresos, debe ser capaz también de interactuar con un sistema de menús u opciones mediante un teclado, un ratón o una pantalla táctil, saber navegar a través de documentos hipertextuales sin perderse, conocer los mecanismos y procedimientos para grabar imágenes, procesarlas y difundirlas en un sitio web, poseer las destrezas para buscar y encontrar en la Red aquel dato o información que necesita para resolver un problema, saber discriminar y otorgar significado a las numerosas informaciones que llegan diariamente por múltiples medios, escribir un documento y enviarlo por correo electrónico o por SMS, participar en un foro expresando su opinión, y, en fin, subir fotos, vídeos o presentaciones para compartirlos con otras personas en una red social, etc.

La alfabetización según Paulo Freire ayuda al sujeto a emanciparse, a reconocer la realidad que le circunda y, en consecuencia, a reflexionar sobre la misma y actuar para transformarla; representar la adquisición de los recursos intelectuales necesarios para interactuar tanto con la cultura existente como para recrearla de un modo crítico y emancipador, es un derecho y una necesidad de los ciudadanos de la sociedad informacional.

El profesor, por su parte, y en consonancia con lo anterior, debe ser crítico, reflexivo y autónomo con capacidad para plantear alternativas pedagógicas que cambian el rol de proveedor de información a facilitador del aprendizaje para formar personas que gestionen sus propios aprendizajes, adopten una autonomía creciente y dispongan de herramientas intelectuales que les permita un aprendizaje continuo a lo largo de la vida.

Los docentes tienen que familiarizarse con las tecnologías, saber qué recursos existen, dónde buscarlos, y tener habilidad para integrarlos en sus clases, aprender nuevos métodos de enseñanza y evaluación; deben conocer estrategias didácticas que lleven a sus estudiantes usar las tecnologías en las clases, pues la mayor parte de ellos las conocen bien, pero no las emplean para propósitos académicos, pues tienen una capacidad de atención muy corta y están acostumbrados a una información superficial y filtrada (Meter, 2004). 
Estos hábitos y habilidades deben ser desarrollados en los futuros docentes; primero para su propia formación y en segunda instancia para que estén en capacidad de desarrollarlos en sus futuros alumnos, cuando se inserten en el mundo laboral. Por tanto, las instituciones de formación docente enfrentan un doble desafío: preparar a los futuros docentes para que utilicen metodologías innovadoras para incorporar las TIC y por otro lado, para que la formación que ellos reciben las implementen a modo de modelar sus usos y vivencias como estudiantes.

Es la formación inicial el momento ideal para predisponer positivamente a los maestros hacia la integración curricular de las TIC, ya que la formación del profesorado en ejercicio suele estar más encaminada a modificar actuaciones y prácticas concretas en un momento dado que a generar actitudes abiertas y favorables tanto a la innovación educativa con TIC, como a la cada día más imprescindible alfabetización digital.

En ese proceso de adquisición de hábitos y habilidades en el uso de las TIC es importante tener en cuenta lo que según Gutiérrez (2012) representa tres peligrosos supuestos en ese componente de la formación de docentes. El primero parte de la relación directa entre tecnologías y educación como una obligación de los tiempos en que vivimos; este supuesto se traduce en adaptar el sistema educativo a las exigencias de las nuevas Tecnologías de la Información y la Comunicación, cuando serían éstas las que habría que adaptar a las exigencias de una educación libre y democrática. El segundo supuesto es que las TIC constituyen simples recursos educativos que el profesor debe saber manejar, medios transparentes que se nos presentan sin ninguna ideología implícita, que no influyen en la filosofía de la educación ni en la idiosincrasia de los procesos de enseñanzaaprendizaje. Se minimiza, por tanto, la importancia de las TIC como medios de difusión de una cultura, como agentes educativos per se, en entornos de educación informal, y se evita que el profesorado aborde el análisis crítico y reflexivo de sus aspectos positivos y negativos para la sociedad en general. El tercer y último supuesto da a entender que el uso de Internet, los ordenadores y dispositivos multimedia interactivos favorecen el aprendizaje y supone innovación educativa; pero hay que recordar que tanto los viejos como los nuevos medios pueden servir para innovar así como para reforzar los modelos comunicativos unidireccionales y las pedagogías transmisoras hasta ahora predominantes en la enseñanza tradicional.

Los futuros docentes que se están formando en las diferentes instituciones encargadas de ello, son según Tapscott (1999) la generación Net que es la primera generación que crece rodeada de tecnología digital, y para quienes la tecnología no representa ninguna amenaza sino un entorno completamente natural a su experiencia cotidiana; según Prensky (2001) son llamados nativos digitales, hablantes nativos del lenguaje digital de los computadores, los videojuegos y la Internet; y según Howe y Strauss (2000) los Millennials, generación que nació a partir de los años 80 en un contexto donde las tecnologías digitales forman parte de su vida cotidiana, es adepta a los ordenadores, extremadamente creativa con la tecnología y muy acostumbrada a las multitareas en un mundo donde las conexiones ubicuas se dan por hecho.

Según Pedró, (2006) existen tres razones que parecen indicar que los Millennials se transformarán en una preocupación creciente para las instituciones educativas y para los decisores políticos en el futuro que son: las implicaciones del uso intensivo de las tecnologías sobre las capacidades intelectuales y cognitivas, los cambios en las prácticas culturales y en los estilos de vida, y las eventuales contradicciones que emergen de las diferencias en términos de uso dentro y fuera de las aulas por parte de los adolescentes.

El uso continuo de las tecnologías digitales tiene importantes implicaciones en el desarrollo de las competencias intelectuales y de las capacidades cognitivas (Prensky, 2001); los Millennials dominan los medios digitales y los consumen de una forma mucho menos controlables por los adultos, ya sean familias o profesores, puesto que son totalmente autónomos en cuanto a lo que quieren ver, descargar o cargar; desde que los ordenadores e internet entraron a las casas de los alumnos y se transformaron en un aparato doméstico más para muchas familias, las competencias tecnológicas de los alumnos crecieron exponencialmente a través del aprendizaje.

Actualmente existe una serie de referentes internacionales que sirven como guía para la implementación de las TIC en la formación inicial docente entre los cuales se encuentra la propuesta de la UNESCO (2008), que ofrece directrices para planear programas de formación de profesores y selección de cursos que permiten prepararlos para desempeñar un papel esencial en la capacitación tecnológica de los estudiantes. Este referente contempla tres etapas sucesivas para determinar la evolución de las capacidades de los profesores en el uso de las TIC con sus estudiantes que son: la alfabetización tecnológica, la profundización del conocimiento y la creación de conocimiento. La primera consiste en capacitar a los estudiantes para usar las TIC con el objeto de aprender de manera eficiente; la segunda implica capacitar a los estudiantes para adquirir conocimiento profundo de las materias escolares, de tal modo que pueda aplicarlas para resolver problemas reales y complejos; la tercera y última procura capacitar a los estudiantes, ciudadanos y a la fuerza de trabajo que más tarde constituirá, para crear el nuevo conocimiento requerido por una sociedad más armoniosa, plena y próspera.

Este mismo organismo internacional estableció las condiciones esenciales para el aprovechamiento efectivo de las nuevas tecnologías de la información y comunicación en la educación (UNESCO, 2004): 
- Alumnos y docentes deben tener suficiente acceso a las tecnologías digitales y a Internet en las salas de clases e instituciones de formación y capacitación docente.

- Alumnos y docentes deben tener a su disposición contenidos educativos en formato digital que sean significativos, de buena calidad y que tomen en cuenta la diversidad cultural.

- Los docentes deben poseer las habilidades y conocimientos necesarios para ayudar a los alumnos a alcanzar altos niveles académicos mediante el uso de los nuevos recursos y herramientas digitales.

Solo mediante la transformación del contexto de uso de las TIC se logrará un impacto considerable dirigido a innovar la enseñanza y mejorar el aprendizaje al igual que se podrán adquirir las competencias tecnológicas necesarias. (Coll, (2008).

Otro referente que existe lo constituye los estándares de la International Society for Technology Education (ISTE), que tienen amplia difusión y ya han sido adoptados por diversos países que los han ido adaptando a sus instituciones. La ISTE propicia la innovación a través de la creación de nuevos ambientes de aprendizaje, mucho más cercanos a las actuales formas de aprender y enseñar que ofrecen las TIC. Algunas claves de la propuesta de ISTE son: los aprendizajes centrados en los estudiantes, el fomento de los ambientes interactivos y multimediales, la implementación del trabajo colaborativo y el aprendizaje en torno a problemas reales y significativos.

A nivel de la Unión Europea se encuentran los referentes de European Pedagogical ICT Licence cuyo propósito central es desarrollar un proceso de acreditación de profesores para el uso de las TIC en ambientes pedagógicos, tanto para docentes en formación inicial como en ejercicio.

A nivel de Latinoamérica uno de los principales referentes que se tiene es el de la Red Enlaces de Chile, que propone una serie de estándares TIC para la formación inicial docente. Esta propuesta define un marco preciso y consensuado respecto a la preparación de los futuros docentes en diversos aspectos relacionados con las tecnologías, tomando en consideración su uso instrumental, curricular y en general su impacto en la sociedad.

En general todos los países han realizado reformas educativas que incluyen la incorporación de las tecnologías y la preparación de los maestros para integrarlas en el aula tomado como referencias varias de las propuestas anteriores; pero no es suficiente con preparar usuarios competentes y consumidores ávidos de tecnología digital sino se preparan personas que puedan conseguir un desarrollo más justo y más humano de la sociedad de la información.

Es aquí donde radica la importancia de la preparación de los futuros docentes en el uso de las TIC, pues se sabe que las nuevas generaciones son usuarios innatos de las tecnologías, hacen un uso instrumental de estas en su vida diaria, pero las capacidades potenciales asociadas a sus características como son el trabajo colaborativo, la adaptabilidad, el procesamiento de información de múltiples fuentes deben ser desarrolladas mediante un enfoque global en el sistema educativo, la futura generación debe ser guiada en su alfabetización digital.

A manera de conclusión, las características y el ambiente en que se desenvuelven las nuevas generaciones y las políticas y lineamientos trazados por organismos nacionales e internacionales comprometidos con la educación, de alguna manera son factores que deben ser aprovechados por las instituciones educativas formadoras de profesores para que el conocimiento y uso de las TIC sea parte de su desempeño profesional lo cual acarrea implicaciones cognoscitivas, sociológicas y pedagógicas que le deben coadyuvar para que desde su quehacer asuma posiciones críticas, reflexivas y sea autónomo y creativo, planteando nuevas alternativas pedagógicas que transformen su rol tradicional y el de aprendiz.

\section{Referencias}

Area, M. (2012). Alfabetización digital en la Sociedad Digital. En M. Area, A. Gutierrez, \& F. Vidal, Alfabetización digital y Competencias Informacionales (pág. 225). Madrid: Ariel S.A.

Centro de Educación y Tecnología del Ministerio de Educación de Chile ENLACES) (2008) Estándares TIC para la formación inicial docente: Una propuesta en el contexto chileno, (OREALC/UNESCO Santiago).

Coll, C. (2008). Aprender y enseñar con las TIC: expectativas, realidad y potencialidades en Los Desafíos de las TIC para el cambio Educativo p 120 - 121) Fundación Santillana.

EPICT (2006). European pedagogical ICT licence: Concept description: EContent,

http://www.epict.org/about_epict/files/EPICT\%20content $\% 20$ description.pdf.

Gutierrez, A (2012). Formación del profesorado para la alfabetización múltiple en Alfabetización digital y competencias informacionales. Fundación telefónica, Barcelona, España.

Howe, N., \& Strauss, W. (2000). Millennials rising: The next greatest generation. New York: Vintage Books.

International Society for Technology in Education. (2007). ISTE Standards Students. Obtenido de

http://www.iste.org/docs/pdfs/20-14_ISTE_StandardsS_PDF.pdf

Meter, Dirr J. (2004), Desarrollo social y educativo con las nuevas tecnologías, en Nuevas tecnologías y Educación, Martínez, F., y Prendes, M. (coord), Madrid:Pearson.

Organización de las Naciones Unidas para la Educación, la Ciencia y la Cultura (UNESCO). (2008) Estándares UNESCO de Competencia en TIC para Docentes (ECD-TIC). Londres.

Pedró, F (2006) Aprender en el nuevo Milenio: Un desafío a nuestra visión de las tecnologías y la enseñanza. Consultado en http://idbdocs.iadb.org/wsdocs/getdocument.aspx?docnum=84 8274 .

Prensky, Mark (2001): "Digital Natives, Digital Immigrants. Part 1", en On the Horizon, vol. 9 , n. ${ }^{\circ} 5$.

Ramirez Culebro C.M (2012) Análisis de las competencias básicas en tecnologías de la información y la comunicación (TIC) del profesorado de educación primaria: Un plan de formación. Municipio de Comitán, Chiapas, México. Tesis doctoral. Doctorado en Educación Universidad Autónoma de Barcelona. p 48.

Serres, M. (2012). Pulgarcita. Paris, Francia. Traducción hecha por Luis Alfonso Palauc.

Tapscott, D. (1998). Creciendo en un entorno digital: La generación Net. México:McGraw-Hill. 